\title{
Impact of microstructural evolutions during thermal aging of Alloy 625 on its monotonic mechanical properties
}

\author{
Lorena Mataveli Suave $^{1,2}$, Denis Bertheau ${ }^{1}$, Jonathan Cormier ${ }^{1, \text { a }}$, Patrick Villechaise ${ }^{1}$, Aurélie Soula ${ }^{3}$, Zéline Hervier ${ }^{4}$, \\ and Johanne Laigo 5 \\ ${ }^{1}$ Institut Pprime, CNRS - ENSMA - Université de Poitiers, UPR CNRS 3346, Department of Physics and Mechanics of \\ Materials, ENSMA - Téléport 2, 1 avenue Clément Ader, BP. 40109, 86961 Futuroscope Chasseneuil Cedex, France \\ ${ }^{2}$ Aircelle - SAFRAN group, Materials and Process Department, route du pont VIII, 76700 Gonfreville-L'Orcher, France \\ ${ }^{3}$ Aircelle - SAFRAN group, Materials and Processes Department, 50 rue Pierre Curie, BP. 50042, 78371 Plaisir Cedex, \\ France \\ 4 Turbomeca - SAFRAN group, Materials Processes \& Investigations Department, 64511 Bordes Cedex, France \\ 5 Snecma - SAFRAN group, Materials and Process Department, Site de Villaroche, Rond-Point René Ravaud, \\ 77550 Moissy-Cramayel, France
}

\begin{abstract}
Alloy 625 is widely used for petrochemical, marine and aerospace applications owing to its outstanding corrosion and mechanical properties at high temperatures. However, this alloy is prone to complex microstructure evolutions above $500^{\circ} \mathrm{C}$ that may impact its mechanical properties. In this study, the impact of its microstructure evolutions occurring upon thermal aging on the monotonic mechanical properties has been studied. Thermal exposures of up to $\sim 2000$ hours in the $550{ }^{\circ} \mathrm{C}-900^{\circ} \mathrm{C}$ temperature range have been investigated. TTT diagrams of the $\delta$ and $\gamma^{\prime \prime}$ phases were established based on high resolution scanning electron microscopy observations. The evolutions of secondary carbides distributions were also followed. It has been observed a steep increase of the room temperature micro-hardness after overagings performed at $650{ }^{\circ} \mathrm{C}$ and $700^{\circ} \mathrm{C}$ due to the precipitation of the $\gamma^{\prime \prime}$ phase. Moreover, it is clearly demonstrated a strengthening effect of the $\delta$ phase observed after long term thermal exposures at temperatures in excess of $700^{\circ} \mathrm{C}$. Finally, the impact of a thermal aging in the $\gamma^{\prime \prime}$ precipitation domain on the tensile properties was evaluated from room temperature up to $800^{\circ} \mathrm{C}$. It is shown that the loss of high temperature ductility is not correlated to the precipitation of grain boundary secondary carbides.
\end{abstract}

\section{Introduction}

Inconel $^{\mathrm{TM}} 625$ is a nickel-based superalloy developed close to 60 years ago to achieve a good combination of mechanical strength, fracture toughness, fabricability, weldability and corrosion resistance under aggressive environments both at room and high temperatures $[1,2]$. This alloy is widely used in the petrochemical, marine, nuclear, power generation and aerospace industries [1-7]. In the aerospace industry, alloy 625 is used as turbine shrouds, spray bars, hydraulic tubing, armoring and thrust reversers systems. This alloy is nowadays facing a renewed attention for the design and manufacturing of plugs for the exhaust parts in new generations of civil aeroengines due to the increase in operating temperatures, temperatures which will prevent engine manufacturers from using Tibased alloys.

Since these aeroengines components are submitted to complex thermomechanical histories resulting from the very different operating conditions encountered during regular flights, the microstructure of alloy 625 is very

\footnotetext{
${ }^{a}$ Corresponding author: jonathan.cormier@ensma.fr
}

likely to evolve with possible consequences on the mechanical properties and on its in-service durability. Indeed, while alloy 625 is a solid solution strengthened alloy in the as-heat treated state thanks to its high chromium and molybdenum contents [1], this alloy was proved to be sensitive to the precipitation of intermetallic phases such as $\mathrm{Ni}_{2}(\mathrm{Cr}, \mathrm{Mo})$ of $\mathrm{Pt}_{2} \mathrm{Mo}$ structure $[5,6,8]$ or such as the $\mathrm{Ni}_{3} \mathrm{Nb} \gamma^{\prime \prime}$ phase of $\mathrm{DO}_{22}$ structure due its non-negligible niobium content [3,5-10]. From the open literature, six main phases can be found in the austenitic $\gamma$ matrix after various types of thermal exposure $\left(\gamma^{\prime \prime}\right.$, $\delta$ and $\mathrm{Ni}_{2}(\mathrm{Cr}, \mathrm{Mo})$ intermetallic phases, $\mathrm{M}_{6} \mathrm{C}$ and $\mathrm{M}_{23} \mathrm{C}_{6}$ secondary carbides, $\mathrm{MC}$ primary carbides) and over seven minor precipitations (rich $\alpha-\mathrm{Cr}$ particles, $\mu$ TCP particles, Laves particles, Si-rich particles...) were identified to nucleate/decompose/transform upon thermal aging $[1,3$, 5-16]. The interested reader is referred to a recent paper from the authors summarizing phases evolutions in the $550{ }^{\circ} \mathrm{C}-900^{\circ} \mathrm{C}$ temperature range, and analyzing the impact of the forming process on the precipitation kinetics [17]. These microstructure evolutions were found to greatly impact the room and high temperature mechanical properties such as hardness and tensile 
strength through the precipitation of $\gamma^{\prime \prime}$ and $\mathrm{Ni}_{2}(\mathrm{Cr}, \mathrm{Mo})$ phases $[5,10,11,13,16,18,19]$ or toughness and ductility through the combined impacts of the precipitation of secondary carbides $\left(\mathrm{M}_{6} \mathrm{C}, \mathrm{M}_{23} \mathrm{C}_{6}\right)$ and of the $\mathrm{Ni}_{2}(\mathrm{Cr}, \mathrm{Mo})$ intermetallic phase or even TCP phases $[5,11,13,16,18$, 20]. As an example, a spectacular increase (over a factor 2.5 ) of the $0.2 \%$ yield stress (YS) was observed after long thermal agings performed in the $773 \mathrm{~K}-923 \mathrm{~K}$ (500$\left.650^{\circ} \mathrm{C}\right)$ temperature range due to the $\gamma^{\prime \prime}+\mathrm{Ni}_{2}(\mathrm{Cr}, \mathrm{Mo})$ precipitation $[5,7,11,16]$.

Within this context, the aim of the present article is to investigate the impact of microstructure evolutions occurring in the $5500^{\circ} \mathrm{C}-900^{\circ} \mathrm{C}$ temperature range on the room temperature (RT) microhardness. In addition, the impact of a thermal aging performed in the $\gamma^{\prime \prime}$ precipitation domain on the tensile properties from RT up to $800^{\circ} \mathrm{C}$ will be analyzed.

\section{Material and mechanical testing}

\subsection{Materials, thermal overagings and microstructure characterizations}

In the present investigation, all samples were machined by EDM (Electron Discharge Machining) from an as-rolled + solution treated sheet whose thickness is $0.8 \mathrm{~mm}$. This sheet was supplied by Haynes International in a millannealed state (mill annealing performed at a maximum temperature of $1038^{\circ} \mathrm{C}+/-4{ }^{\circ} \mathrm{C}$ ). The chemical composition of the sheet is $\mathrm{Ni}-21.28 \mathrm{Cr}-8.7 \mathrm{Mo}-3.83 \mathrm{Fe}-3.58 \mathrm{Nb}-$ 0.27Mn-0.26Al-0.30Si-0.28Ti-0.029C-0.007Ta (wt.\%). Phosphorous and sulphur contents were respectively below 0.005 and $0.002 \%$ (wt.\%). In this as-received state, the grain size excluding twin boundaries is $\sim 12.8 \mu \mathrm{m}$ (close to ASTM 10). The volume fraction and average size of secondary carbides were measured to be $0.77 \%$ and $0.32+/$ $-0.11 \mu \mathrm{m}$ respectively in this as-received state [17]. Very few primary carbides were detected. The as-received sheet was found to be very weekly textured using EBSD characterizations (texture index 2.4) $[17,19]$.

Aging heat treatments under air were performed using four different furnaces, and samples whose dimensions were $20 * 20 \mathrm{~mm}^{2}$. The aging temperature of the samples was controlled with $\mathrm{a}+/-1{ }^{\circ} \mathrm{C}$ precision using a K-type thermocouple positioned in the immediate vicinity of the samples. Heat treatments were performed in the $550^{\circ} \mathrm{C}-$ $900^{\circ} \mathrm{C}$ temperature range for durations up to $\sim 2000$ hours. Forty-six aging conditions were investigated. After each aging heat treatment, samples were air quenched. These samples used to analyze the microstructure evolutions as a function of the thermal exposure length and temperature were also used subsequently for RT microhardness characterizations.

To characterize the microstructure evolutions of alloy 625 as a function of the thermal aging, samples were mechanically polished up to a mirror finish (final polishing using a $1 \mu \mathrm{m}$ diamond paste). A special care was taken to remove all the oxidized layers of the samples that had developed upon thermal aging. Samples were subsequently electrochemically polished using perchloric acid (10 pct. in volume) in methanol. This preparation allows both the characterization of the granular structure of the alloy and of different classes of precipitates (MC primary carbides, $\mathrm{M}_{6} \mathrm{C}$ and $\mathrm{M}_{23} \mathrm{C}_{6}$ secondary carbides, $\gamma^{\prime \prime}$ phase and $\delta$ phase).

Particles observations were performed using a JEOL JSM $^{\mathrm{TM}}$ 7000F Field Emission Gun SEM using secondary (SEI) and backscattered (BSE) electron imaging modes. Observations were performed using both low magnifications (below $\times 5000$ ) in BSE mode for the carbides characterization while $\delta$ and $\gamma^{\prime \prime}$ phases were characterized using the SEI mode. Observations were performed using an acceleration voltage of $25 \mathrm{kV}$.

\subsection{Microhardness characterizations}

Microhardness characterizations were performed at room temperature using the heat treated coupons after they had been polished up to a mirror finish (i.e. without any chemical etching or electrochemical polishing). They were performed using a Fisher HM T3 instrumented Vickers microindentor where both the evolution of the applied force and penetration depth can be continuously followed during each indentation. Experiments were performed according to the following procedure: 1) loading in 15 seconds up to a $300 \mathrm{mN}$ applied force; 2) a 3 seconds dwell at maximum load; 3) unloading in 15 seconds. For each sample, arrays of 49 indentations at least were performed. A minimum distance of $57 \mu \mathrm{m}$ between each individual indentation was used to avoid any influence of the neighboring indentations on the locally measured hardness. For each microstructural state, an arithmetic average of all these 49 indentations will be provided, and the error bars for each experimental point will correspond to $+/-$ the standard deviation. It has to be noted that indentations performed in primary carbides have been removed from the statistics (less than one indentation per sample). In the softest state (i.e. the as-received state), the penetration depth was $\sim 2 \mu \mathrm{m}$. Hence, using such a load with such a grain size $(\sim 12-13 \mu \mathrm{m})$, microhardness measurements employed here are mainly sensitive to the intragranular precipitation and, to a lesser degree, to the grain size.

\subsection{High temperature tensile tests}

Tensile tests were performed using flat samples whose gage length and gage section are $15 \mathrm{~mm}$ and 4 by $0.8 \mathrm{~mm}^{2}$ respectively. The total length of the sample was $62 \mathrm{~mm}$. Samples were machined with the gage length aligned along the rolling direction of the sheet. Before any tensile test, each face and edge of the samples were carefully polished up to a $4000 \mathrm{SiC}$ grade and the sections were carefully measured using a profilometer.

Tensile tests were performed at RT, $200^{\circ} \mathrm{C}, 350{ }^{\circ} \mathrm{C}$, $550{ }^{\circ} \mathrm{C}, 650^{\circ} \mathrm{C}, 700^{\circ} \mathrm{C}, 750^{\circ} \mathrm{C}$ and $800^{\circ} \mathrm{C}$. They were performed using an Instron 8562 electromechanic machine equipped with a high temperature contact extensometer. Heating was ensured with a two-zone resistive furnace. The following tensile testing procedure was used: heating at $20^{\circ} \mathrm{C} \cdot \mathrm{min}^{-1}$ followed by a 30 minutes soak time before starting the tensile test at a constant displacement rate of $15.10^{-3} \mathrm{~mm} . \mathrm{s}^{-1}$ up to failure. The cooling down to RT after samples failure was also performed at $20^{\circ} \mathrm{C} \cdot \mathrm{min}^{-1}$. 

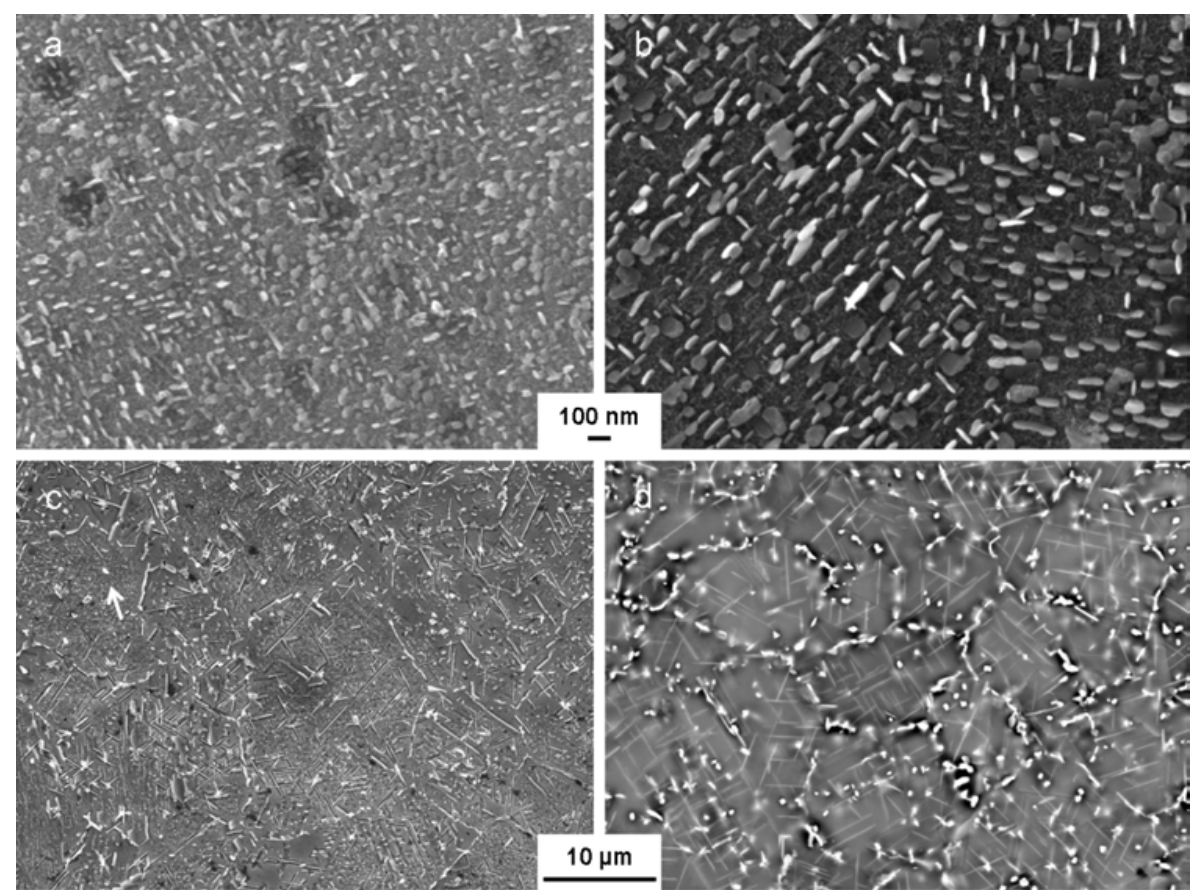

Figure 1. Microstructures observed after $500 \mathrm{~h}$ at $650^{\circ} \mathrm{C}(\mathrm{a}), 2000 \mathrm{~h}$ at $650{ }^{\circ} \mathrm{C}(\mathrm{b}), 100 \mathrm{~h}$ at $750{ }^{\circ} \mathrm{C}$ (c) and $100 \mathrm{~h}$ at $800^{\circ} \mathrm{C}(\mathrm{d})$. Note the growth of the $\gamma^{\prime \prime}$ particles between (a) and (b) with an increased aging time, the coexistence of both $\delta$ and $\gamma^{\prime \prime}$ phases at $750^{\circ} \mathrm{C}$ (c) and intragranular $\delta$ platelets extending throughout all the grain at $800^{\circ} \mathrm{C}(\mathrm{d})$.

These tensile tests were performed on both the as-received sheet and after one part of this sheet had been exposed to a 500 hours aging at $650^{\circ} \mathrm{C}$.

\section{Impact of thermal overaging on microstructure and RT microhardness evolutions}

Figure 1 shows four examples of intermetallic precipitation in alloy 625 after thermal exposures at $650{ }^{\circ} \mathrm{C}$ (Figs. 1a and 1b), at $750^{\circ} \mathrm{C}$ (Fig. 1c) and at $800^{\circ} \mathrm{C}$ (Fig. 1d). A more exhaustive microstructure characterization has already been performed recently by L. Mataveli Suave et al. [17]. These microstructure states have been especially chosen in the present article to illustrate the main type of microstructure evolutions that are likely to control the subsequent mechanical upon thermal exposure. It is observed in Figs. $1 \mathrm{a}$ and $1 \mathrm{~b}$ the precipitation of intragranular $\mathrm{Ni}_{3} \mathrm{Nb} \gamma^{\prime \prime}$ particles. These particles are also observed to grow during increased exposure time at this temperature (compare Figs. 1a and 1b). The coarsening process of $\gamma^{\prime \prime}$ particles in Alloy 625 was observed to follow the Lifshitz-Slyozov-Wagner (LSW) theory once a lens morphology of the precipitate is reached. An apparent activation energy of $358 \mathrm{~kJ} . \mathrm{mol}^{-1}$ for this coarsening process has been determined previously [17]. At $750^{\circ} \mathrm{C}$, both $\gamma^{\prime \prime}$ and $\delta$ precipitation is observed, especially for thermal exposures below $\sim 1000$ hours. Figure 1c clearly shows the intragranular precipitation of $\delta$ needles as well as remaining coarse $\gamma^{\prime \prime}$ particles (see white arrow in Fig. 1c) after $100 \mathrm{~h}$ at $750^{\circ} \mathrm{C}$. One should also notice the precipitation of $\mathrm{M}_{23} \mathrm{C}_{6}$ intergranular secondary carbides. After thermal exposures at $800^{\circ} \mathrm{C}$, the sole intragranular $\delta$

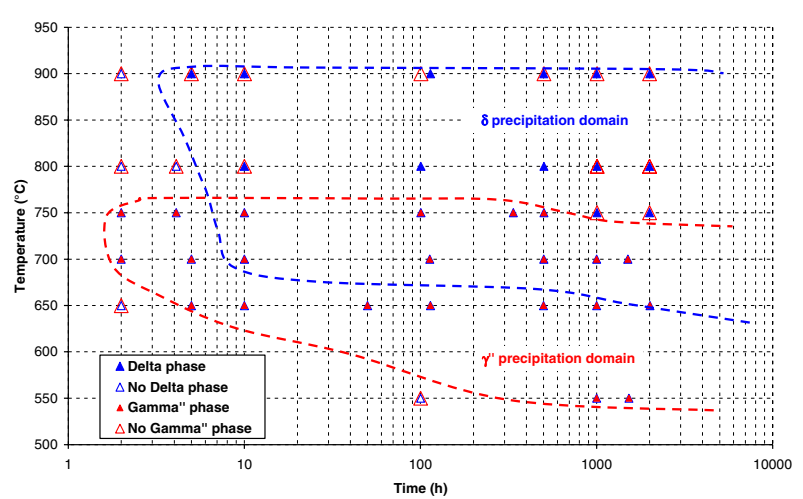

Figure 2. TTT diagram of the $\gamma^{\prime \prime}$ and $\delta$ phases in the studied alloy 625.

precipitation has been observed, without any $\gamma^{\prime \prime}$ particles, even after short exposures. $\delta$ platelets have been observed to extend throughout all the grain for thermal exposures longer than 100 hours at this temperature (see e.g. Fig. 1d). In addition, both intergranular and intragranular precipitation of $\mathrm{M}_{23} \mathrm{C}_{6}$ and $\mathrm{M}_{6} \mathrm{C}$ carbides was observed at $800{ }^{\circ} \mathrm{C}$ (see white grain boundaries particles in Fig. 1d).

The TTT diagram for the $\delta$ and the $\gamma^{\prime \prime}$ precipitation established from high resolution SEM observations of all the investigated thermal exposures is presented in Fig. 2. The $\delta$ phase is observed to precipitate in the $650^{\circ} \mathrm{C}-$ $900{ }^{\circ} \mathrm{C}$ temperature domain and preferentially between $700^{\circ} \mathrm{C}$ and $800^{\circ} \mathrm{C}$, while the $\gamma^{\prime \prime}$ phase was found to precipitate in the $550{ }^{\circ} \mathrm{C}-750^{\circ} \mathrm{C}$ temperature domain, with a precipitation nose between $650^{\circ} \mathrm{C}$ and $700^{\circ} \mathrm{C}$. These precipitation domains are in quite good agreement with data extracted from the open literature $[2,11,12,14]$. Some differences in the $\delta$ precipitation nose were however 


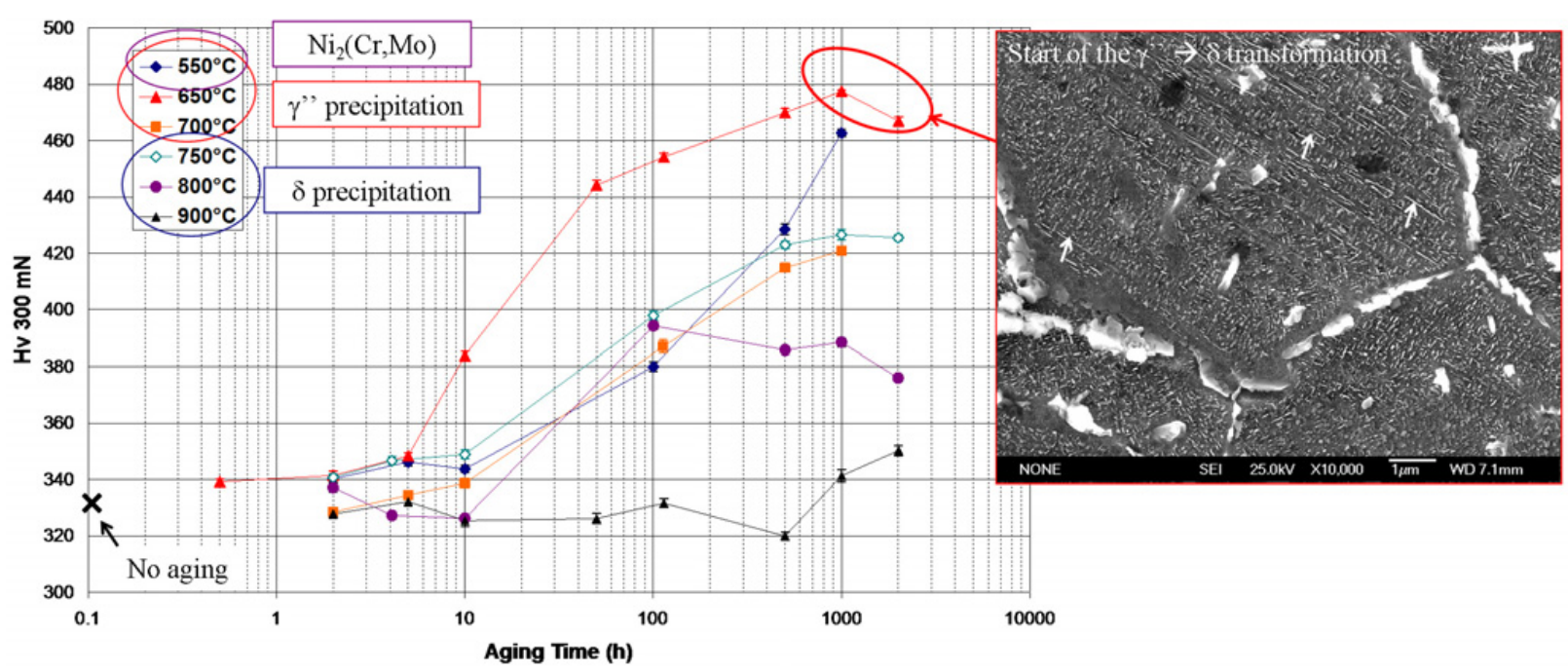

Figure 3. Evolution of the RT microhardness after long-term thermal exposure in the $550{ }^{\circ} \mathrm{C}-900^{\circ} \mathrm{C}$ temperature range and illustration of the impact of the $\gamma^{\prime \prime} \rightarrow \delta$ transformation at $650^{\circ} \mathrm{C}$.

noted between the present study and other studies, see e.g. [21].

The evolution of RT microhardness is shown in Fig. 3. The initial RT hardness without any thermal exposure is $\mathrm{Hv}=331+/-2$. It is observed a hardness increase for all aging temperatures, except at $900{ }^{\circ} \mathrm{C}$ where the RT hardness remains almost stable, with a possible final increase due to the $\delta$ particle growth. At lower temperatures, a continuous increase in Vickers hardness is observed up to $\sim 1000$ hours of thermal exposure, whatever the temperature. At the lowest temperature $\left(550^{\circ} \mathrm{C}\right)$, this hardness progressive and continuous increase is correlated to the precipitation of $\mathrm{Ni}_{2}(\mathrm{Cr}, \mathrm{Mo})$ particles[5,6,8] and to the $\gamma^{\prime \prime}$ precipitation over 1000 hours [17].

At $650{ }^{\circ} \mathrm{C}$, a sluggish increase in hardness is observed for the first 5 hours. This increase was observed already after 30 minutes despite no $\gamma^{\prime \prime}$ particles could have been observed using high resolution SEM observations (Fig. 2). After 5 hours, a steep increase in hardness correlated to the $\gamma^{\prime \prime}$ precipitation is observed. One can also observe that the highest RT hardnesses are obtained after $650^{\circ} \mathrm{C}$ thermal exposures, i.e. at a temperature where only the $\gamma^{\prime \prime}$ phase can be encountered (Fig. 2). Microhardness is indeed peaking after a 1000 hours thermal exposure at $650{ }^{\circ} \mathrm{C}$ and a subsequent small decrease is observed when increasing the exposure up to 2000 hours. This small decrease has been correlated to the onset of the $\gamma^{\prime \prime} \rightarrow \delta$ transformation occurring at this temperature for very long exposures. This transformation is illustrated in the micrograph shown in Fig. 3 were first evidences of $\delta$ formation are highlighted by white arrows.

Thermal exposures at $700^{\circ} \mathrm{C}$ and $750^{\circ} \mathrm{C}$ lead to a continuous increase of RT Microhardness due to first the $\gamma^{\prime \prime}$ precipitation simultaneously to the $\delta$ one (see Fig. 2), and then to the growth of the $\delta$ particles within the grains. The hardness evolution also follows a similar trend up to 100 hours of exposure at $800^{\circ} \mathrm{C}$, and then, a stabilization (or even a small decrease) is observed.
From these RT microhardness characterizations, it is clearly demonstrated that thermal exposures in the $550^{\circ} \mathrm{C}-$ $800^{\circ} \mathrm{C}$ temperature range lead to an improvement of the monotonic properties. The most significant strengthening within the investigated conditions results from the $\gamma^{\prime \prime}$ precipitation at $650{ }^{\circ} \mathrm{C}$. However, it is also clearly observed here, and probably for the first time, a strengthening provided by the $\delta$ precipitation. Such a strengthening was only supposed in a previous study using alloy 625 [5].

In our opinion, this strengthening may result from a "composite strengthening" since $\delta$ particles are extending throughout all the grain in this small grain alloy 625 . We would expect a different impact of the $\delta$ precipitation on alloy 625 hardness with a coarser grain size. From the present characterizations, it is also observed that RT microhardness is a useful tool to probe microstructure evolutions in addition to conventional microstructure observations using SEM and/or TEM.

\section{Impact of a thermal aging at $650^{\circ} \mathrm{C}$ on the high temperature tensile properties}

Based on the previous RT hardness measurements, it has been chosen to investigate the impact of an aging heat treatment performed at $650{ }^{\circ} \mathrm{C}$ on the high temperature tensile properties. A thermal exposure of 500 hours was chosen based on Fig. 3 since it produces nearly the highest RT hardness with reasonable thermal exposure duration. Compared to the as-received alloy which is only solid solution strengthened, such a thermal exposure before tension tests leads to the precipitation of $\gamma^{\prime \prime}$ particles (Fig. 1a) whose diameter is $\sim 42.5 \mathrm{~nm}$ [17]. In addition, the volume fraction of secondary carbides (mainly $\mathrm{M}_{23} \mathrm{C}_{6}$ ) raised from $0.77 \%$ up to $\sim 4 \%$. As observed in Fig. 4 , these secondary carbides mainly nucleate at grain boundaries.

The effect of this prior aging heat treatment at $650^{\circ} \mathrm{C}$ on the tensile properties at $\mathrm{RT}, 650^{\circ} \mathrm{C}$ and $800^{\circ} \mathrm{C}$ is shown in Fig. 5. It is observed much higher yield and ultimate tensile stresses at $20^{\circ} \mathrm{C}$ and $650^{\circ} \mathrm{C}$ after this prior thermal exposure. These better YS and UTS are 


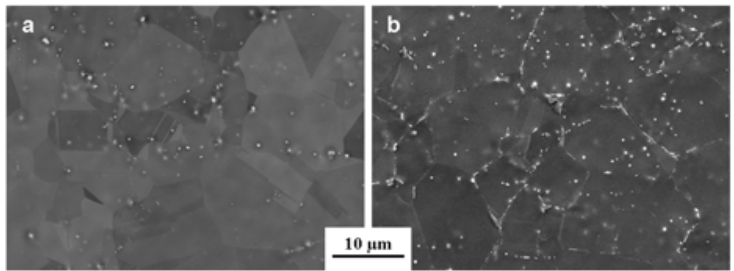

Figure 4. Secondary carbides precipitation in the as-received state (a) and after $500 \mathrm{~h}$ at $650{ }^{\circ} \mathrm{C}$ (b).

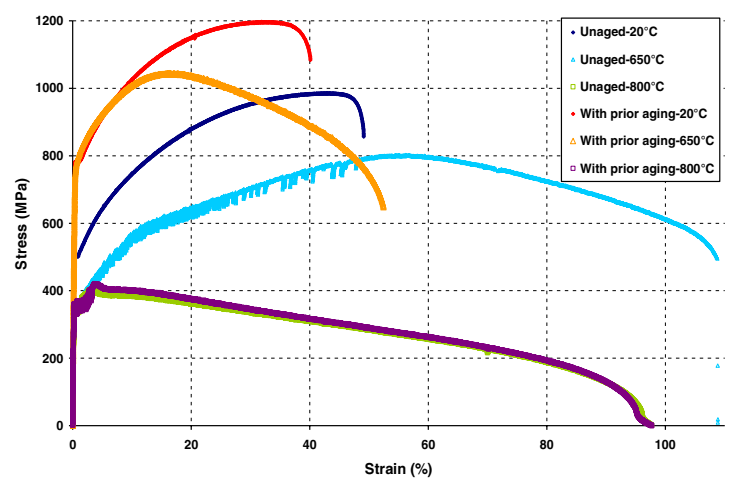

Figure 5. Tensile behavior at $20^{\circ} \mathrm{C}, 650^{\circ} \mathrm{C}$ and $800^{\circ} \mathrm{C}$ in the asreceived state and after a $500 \mathrm{~h}$ thermal exposure at $650^{\circ} \mathrm{C}$.

accompanied by a decrease of the strain to failure at these two temperatures. One of the remarkable results is obtained comparing tensile properties at $800{ }^{\circ} \mathrm{C}$ where no difference can be observed between both state, neither in ductility, nor in YS or UTS. It is also noted that the asreceived alloy exhibit a serrated tensile behavior (the socalled Portevin - Le Chatelier effect) from $200{ }^{\circ} \mathrm{C}$ up to $800{ }^{\circ} \mathrm{C}$ with this strain rate [19]. These serrations are not observed after a prior heat treatment in the $\gamma^{\prime \prime}$ domain has been performed, except at $800^{\circ} \mathrm{C}$ in the very early stages of plastic deformation (i.e. up to $4-5 \%$ of total strain).

The impact of the prior aging heat treatment at $650{ }^{\circ} \mathrm{C}$ on the YS, UTS and ductility evolutions as a function of the temperature is shown in Figs. 6 and 7. It is observed that the YS and UTS are always higher for the alloy submitted to this specific prior thermal exposure. A YS difference of up to a factor of $\sim 2$ is observed in the $200{ }^{\circ} \mathrm{C}-650{ }^{\circ} \mathrm{C}$ temperature range. Above $650^{\circ} \mathrm{C}$, the difference in $\mathrm{YS}$ between these two microstructural states is progressively decreasing up to almost no difference at $800^{\circ} \mathrm{C}$, as already observed in Fig. 5. The reason for the steeper decrease in YS and UTS for the overaged samples results from the progressive dissolution of the $\gamma^{\prime \prime}$ particles above $700^{\circ} \mathrm{C}$ and their transformation into $\delta$ particles (Fig. 2). A complete dissolution of $\gamma^{\prime \prime}$ particles is even obtained at $800^{\circ} \mathrm{C}$ (see Fig. 2). Indeed, as already observed in Fig. 3, microhardness is much more lower at $700{ }^{\circ} \mathrm{C}, 750{ }^{\circ} \mathrm{C}$ and $800^{\circ} \mathrm{C}$ compared to its values at $650{ }^{\circ} \mathrm{C}$.

The ductility follows the inverse trend compared to YS and UTS ones: its value is always higher without any prior thermal exposure. The observed very high ductility at $650{ }^{\circ} \mathrm{C}$ in the as-received state remains to be explained and it will not be further commented. As for YS and UTS, no more difference in ductility is observed during

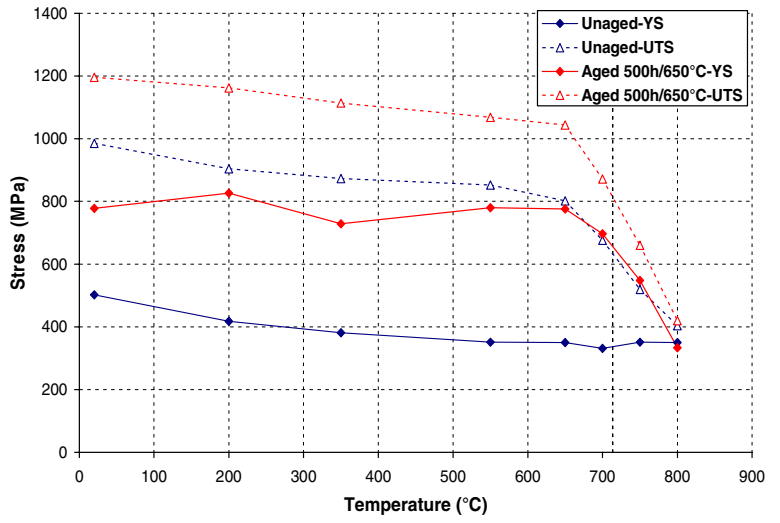

Figure 6. Effect of a prior aging of 500 hours at $650{ }^{\circ} \mathrm{C}$ on the YS and UTS evolutions as a function of temperature.

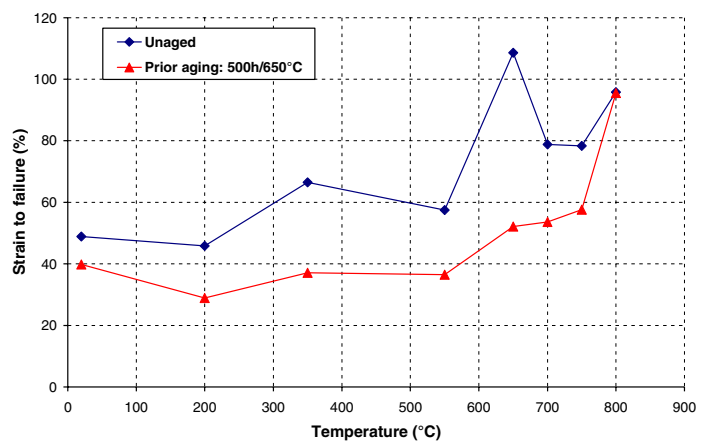

Figure 7. Effect of a prior aging of 500 hours at $650{ }^{\circ} \mathrm{C}$ on the high temperature ductility.

tensile tests at $800^{\circ} \mathrm{C}$. This last result, in addition to no difference in YS and UTS at $800^{\circ} \mathrm{C}$, clearly indicates that the high temperature tensile properties of alloy 625 are not controlled by the grain boundary secondary carbides precipitation. Indeed, no dissolution of secondary carbides occurs at $800^{\circ} \mathrm{C}$ and the additional exposure at this temperature during the tensile test would instead favour an increase in secondary carbide content [17]. Hence, contrary to what has been believed in previous studies [20, 22? ], the decrease in ductility after thermal exposures in the $600{ }^{\circ} \mathrm{C}-750{ }^{\circ} \mathrm{C}$ temperature range does not result from a secondary carbides precipitation, but rather from the intragranular precipitation of the $\gamma^{\prime \prime}$ phase. This result is in rather good agreement with the ones proposed by Kölher [18]. One additional analysis that can be drawn from the present study is that a thermal exposure of $\sim 30$ minutes (the soak time before the tensile test) is enough to erase all the consequences of a 500 hours thermal exposure at $650{ }^{\circ} \mathrm{C}$ from a high-temperaturetensile-properties point of view.

\section{Conclusions}

The impact of thermal exposures on the static mechanical properties of alloy 625 has been studied. The evolution of the room temperature microhardness has been investigated after thermal exposures between $550^{\circ} \mathrm{C}$ and $900^{\circ} \mathrm{C}$ for up to $\sim 2000$ hours. In addition, the impact of a 
500 hours thermal aging at $650^{\circ} \mathrm{C}$ on the high temperature tensile properties has been investigated. As a first main conclusion, thermal exposures in the $550{ }^{\circ} \mathrm{C}-800^{\circ} \mathrm{C}$ temperature increase the RT static mechanical properties. This results from the precipitation of intermetallic $\gamma^{\prime \prime}$ or $\delta$ particles, with a stronger impact of $\gamma^{\prime \prime}$ particles. It is here unambiguously demonstrated a $\delta$ hardening. As a second main conclusion, the $\gamma^{\prime \prime}$ precipitation improves the YS and UTS (up to a factor of two for the YS) and decreases the ductility in the $\mathrm{RT}-750{ }^{\circ} \mathrm{C}$ temperature range. At $800^{\circ} \mathrm{C}$, the dissolution of the $\gamma^{\prime \prime}$ particles restores the as-received tensile properties.

The SAFRAN group (Aircelle, Snecma and Turbomeca companies) is gratefully acknowledged for financial support, for providing the material and for L. Mataveli Suave Master thesis grant.

\section{References}

[1] H.L. Eiselstein and D.J. Tillack, (Ed. TMS, Proceedings of Superalloys 718, 625 and Various Derivatives, Pittsburgh, PA, USA, 1-14), (1991)

[2] L.E. Shoemaker, (Ed. TMS, Proceedings of Superalloys 718, 625, 706 and Derivatives., Pittsburgh, PA, USA, 409-418), (2005)

[3] C. Vernot-Loier and F. Cortial, (Ed. TMS, Superalloys 718, 625 and Various Derivatives. Pittsburgh, PA, USA, 409-422), (1991)

[4] J.M. Rakowski et al., (Ed. TMS, Proceedings of Superalloys 718, 625, 706 and Derivatives., Pittsburgh, PA, USA, 271-286), (2005)

[5] V. Shankar et al., J. Nucl. Mat. 288, 222-232 (2001)

[6] M. Sundararaman, et al., Met. Mat. Trans A, 30A, 41-52 (1999)

[7] C. Thomas and P. Tait, Int. J. Pres. Ves. \& Piping, 59, 41-49 (1994)
[8] M. Sundararaman et al., (Ed. TMS, Proceedings of Superalloys 718, 625, 706 and Derivatives., Pittsburgh, PA, USA, 367-378), (2001)

[9] H.C. Pai and M. Sundararaman, (Ed. TMS, Proceedings of Superalloys 718, 625, 706 and Derivatives., Pittsburgh, PA, USA, 487-495), (2005)

[10] V. Shankar et al., Scripta Mater., 44, 2703-2711 (2001)

[11] C.R. Conder et al., (Ed. TMS, Proceedings of Superalloys 718, 625, 706 and Derivatives., Pittsburgh, PA, USA, 447-458), (1997)

[12] F. Cortial et al., Met. Mat. Trans. A, 26A, 1273-1286 (1995)

[13] N.D. Evans et al., Mat. Sci. Eng., A498, 412-420 (2008)

[14] S. Floreen et al., (Ed. TMS, Proceedings of Superalloys 718, 625 and Various Derivatives, Pittsburgh, PA, USA, 13-37), (1994)

[15] U. Heubner and M. Khler, (Ed. TMS, Proceedings of Superalloys 718, 625 and Various Derivatives, Pittsburgh, PA, USA, 479-488), (1994)

[16] J.F. Radavich and A. Fort, (Ed. TMS, Proceedings of Superalloys 718, 625 and Various Derivatives, Pittsburgh, PA, USA, 635-647), (1994)

[17] L. Mataveli Suave et al., Met. Mat. Trans. A, 45A, 2963-2982 (2014)

[18] M. Khler, (Ed. TMS, Proceedings of Superalloys 718, 625 and Various Derivatives, Pittsburgh, PA, USA, 363-374), (1991)

[19] L. Mataveli Suave, (M.Sc. thesis, ISAE-ENSMA: Chasseneuil du Poitou, France, 2012)

[20] M. Sundararaman, et al., (Ed. TMS, Proceedings of Superalloys 718, 625, 706 and Derivatives., Pittsburgh, PA, USA, 367-378), (1997)

[21] M. Sundararaman et al., Met. Trans. A, 19A, 454465 (1988)

[22] J.K. Chakravartty et al., Mat. Sci. Tech. 28, 702-710 (2012) 